\title{
CURCUMINOID AND TOXICITY LEVELS OF ETHANOL EXTRACT OF JAVANESE GINGER (CURCUMA XANTHORRHIZA) ON BRINE SHRIMP (ARTEMIA SALINA) LARVAE AND ZEBRAFISH (DANIO RERIO) EMBRYOS
}

\author{
GUSTINI SYAHBIRIN ${ }^{1 *}$, NURFADILAWATI ${ }^{1}$, KUSDIANTORO MOHAMAD ${ }^{2}$ \\ ${ }^{1}$ Department of Chemistry, Faculty of Mathematics and Natural Sciences, Bogor Agricultural University, Kampus IPB Dramaga, Bogor \\ 16680, Indonesia. ${ }^{2}$ Department of Anatomy, Physiology and Pharmacology, Faculty of Veterinary Medicine, Bogor Agricultural University, \\ Kampus IPB Dramaga, Bogor 16680, Indonesia. Email: gsyahbirin@yahoo.com, gustinisy@apps.ipb.ac.id
}

Received: 02 December 2016, Revised and Accepted: 29 December 2016

ABSTRACT

Objective: This study was aimed at determining the levels of curcuminoids and analyzing the toxicity of ethanol extracts of Javanese ginger.

Methods: Curcuminoid levels were determined using high-performance liquid chromatography, while the toxicity tests were done on larva of brine shrimp (Artemia salina) by using a brine shrimp lethality test (BSLT) method and embryos of zebrafish (Danio rerio) using a zebrafish embryo acute toxicity (ZFET) method.

Results: The level curcuminoid of ethanol extracts was $10.5 \%$ dry wt., consisting of curcumin at the highest percentage (68.06\%) followed by desmethoxycurcumin $(24.6 \%)$ and bisdemethoxycurcumin (1.41\%). In BSLT method, the lethal concentration 50\% values $\left(\mathrm{LC}_{50}\right)$ value of our ethanol extract was $238 \mathrm{ppm}$, whereas in ZFET method, the $\mathrm{LC}_{50}$ value at 96 hours after fertilization was $80 \mathrm{ppm}$. The ethanol extract of ginger caused major malformations of the pericardial edema of zebrafish embryos at a concentration of $100 \mathrm{ppm}$.

Conclusion: The ethanol extract of Curcuma xanthorrhiza from Bogor contained curcuminoids consisting of curcumin, desmethoxycurcumin, and bisdemethoxycurcumin, with acute toxicity, caused major malformations on the pericardial edema in zebrafish embryos.

Keywords: Curcuma xanthorrhiza, Curcuminoid, Toxicity, Zebrafish embryo acute toxicity.

(c) 2017 The Authors. Published by Innovare Academic Sciences Pvt Ltd. This is an open access article under the CC BY license (http://creativecommons. org/licenses/by/4. 0/) DOI: http://dx.doi.org/10.22159/ajpcr.2017.v10i4.16429

\section{INTRODUCTION}

Curcuma xanthorrhiza, known as temulawak, is a medicinal plant which grows in tropical areas like Indonesia. This plant is commonly grown in home yards. It has been known to have many benefits, particularly health benefits. The rhizome is the part of the plant which is usually used as a medicine. The rhizome of Javanese ginger is believed to have antimicrobial [1], anti-inflammatory [2], antioxidative [3], and antinociceptive properties [4]. Furthermore, a study by Cheah et al. showed that Javanese ginger had a potential as a growth inhibitor of human breast cancer [5].

These various health benefits of Javanese ginger are attributed to its main active components, namely curcuminoid, and essential oils. Curcumin and demetoxycurcumin were reported as the active components in C.xanthorrhiza [6]. The essential oils of Javanese ginger contained sesquiterpenoid compounds ( $\beta$-curcumena, ar-curcumena), xantorizol, and a small amount of camphor [7]. An anti-inflammatory property of ethanol extract of Javanese ginger was reported by Itokawa et al. [8].

A preliminary toxicity test of a substance can be done using a brine shrimp lethality test (BSLT). This toxicity test has been proven to have a correlation with toxicity levels. As an indicator, shrimp larva is very sensitive to the toxic material so that the toxicity of material to shrimp larva can be used as an initial indication of the material's pharmacological effect. The BSLT method has some advantages including the fact that shrimp larva is sensitive to test materials, is easy to grow, and have a short life cycle. In addition, this method is easily performed, fast, and relatively inexpensive. However, there are also some disadvantages of this method. Results of the observation do not show the cause of death or type of abnormality of the test animal.
Therefore, a further test to assess the effects of active compounds on the growth of the test organism, by using a zebrafish embryo acute toxicity (ZFET) test, needs to be done.

Zebrafish (Danio rerio) is an animal originating from Myanmar, Srilanka, and India. Today, this fish is used in many kinds of tests, including toxicity testing. As a test animal, the zebrafish has several advantages, including the fact that this fish is small in size (about 2.5-4 cm), does not need plenty rearing space, has similar morphological and physiological structures to mammals, has external fertilization, and short life cycle. The embryo of this fish is transparent making direct observation in vivo on organ and tissue development possible [9]. In addition, the permeable embryo of zebrafish allows the distribution of active substances into the embryo [10] so that it can be used in a toxicity test. Therefore, toxicity types that can be assessed using the zebrafish bioassay including reproductive toxicity, acute toxicity, neurotoxicity, cardiotoxicity, optical toxicity, endocrine disorders, neurobehavioral toxicity, and vascular toxicity. This fish can also be used in anticancer testing [11].

This study was aimed at determining the level of curcuminoids and evaluating the toxicity of ethanol extracts of $C$. xanthorrhiza using the BSLT and the ZFET bioassays.

\section{METHODS}

Plant determination

C. xanthorrhiza was collected from the Conservation and Cultivation Unit, Biopharmaca Research Center, Bogor, Indonesia, in March 2014. The authenticity of the plant was confirmed by the Botany Division (Herbarium Bogoriense) of the Research Center for Biology Indonesian Institute of Sciences, Cibinong, Bogor, West Java, Indonesia. 


\section{Sample preparation}

Javanese ginger rhizomes were washed in running water, surface dried, and chopped into small pieces. The rhizomes were then dried in an oven at $40^{\circ} \mathrm{C}$ for $24 \mathrm{hrs}$. Dried rhizomes were ground to obtain Javanese ginger powder.

\section{Javanese ginger extraction}

Preparation of Javanese ginger extraction was adopted from Srijanto and Syahbirin [12]. The extraction was done by macerating in $80 \%$ (v/v) ethanol as solvent. The ratio of Javanese ginger and solvent was 1:6. As much as $100 \mathrm{~g}$ of Javanese ginger powder was soaked in $80 \%$ ethanol in a macerator for $3 \mathrm{hrs}$ at $40-45^{\circ} \mathrm{C}$. The ginger bath was filtered using a filter paper to separate the filtrate from its macerate. The resulting filtrate was evaporated using a rotavapor (vacuum evaporator) to obtain a concentrated extract to be used in the next stages.

\section{Determination of curcuminoid level using high-performance liquid chromatography (HPLC)}

Curcuminoid level was measured using adapted method from Jayaprakasha et al. [13]. A $50 \mathrm{mg}$ aliquot of Javanese ginger extract was dissolved in $50 \mathrm{~mL}$ methanol. The solution was diluted 50 times and filtered by using a Millipore $0.45 \mu \mathrm{m}$ filter paper before it was put into HPLC vials. Curcuminoid standard was prepared at a concentration of $0.5 \mu \mathrm{g} / \mathrm{mL} . \mathrm{A} \mathrm{C}_{18}$ reverse-phase column with a visible-ultraviolet detector and $20 \mu \mathrm{L}$ injection volume was used. Elution was done with a flow rate of $1.0 \mathrm{~mL} /$ minute. Methanol (A), acetic acid $2 \%(\mathrm{v} / \mathrm{v}$ ) (B), and acetonitrile $(\mathrm{C})$ were used as the eluent mix. A linear gradient elution was done with a constant A concentration (5\%) and changing concentrations of C in B from 45 to $65 \%$ at zero time to 15 minutes to 65 to $45 \%$ at $15-20$ minutes. The curcuminoid level was measured at wavelength of $425 \mathrm{~nm}$.

\section{Toxicity test of extract using Artemia salina larva}

Preparation of toxicity test of extract using $A$. salina larva was adopted from Meyer et al. [14]. Eggs of $A$. salina were placed in a container filled in with filtered and aerated sea water. The eggs were kept illumination for $48 \mathrm{hrs}$ so that the eggs hatched perfectly. The ethanol extract was dissolved in seawater in a concentration of $2000 \mathrm{ppm}$, and this solution was made the mother solution. This solution was then diluted to the concentrations of $100,200,300,400$, and $500 \mathrm{ppm}$. If the mixture was not clear, $100 \mu \mathrm{L}$ dimethyl sulfoxide (DMSO) was added. Seawater, 10 shrimp larvae, and the Javanese ginger extract were put into each vial. Testing was done using three replicates. Vials were covered with aluminum foil sheet and incubated for $24 \mathrm{hrs}$. Lethal concentration $50 \%$ values $\left(\mathrm{LC}_{50}\right)$ were determined using a correlational curve between $\log ^{10}$ extract concentration (x-axis) and probit value (y-axis).

\section{Toxicity test of extract using zebrafish embryo}

The husbandry and all procedures related with this study were approved by the Ethic Committee of Animal Use and Care, Faculty of Veterinary Medicine, Bogor Agricultural University, under license number 015/KEH/SKE/XI/2014. The toxicity test of extract using zebrafish embryo was adopted from OECD Guidelines [15]. Ethanol extracts of Javanese ginger were dissolved in filtered well water at a concentration of $2000 \mathrm{ppm}$, and this solution was made the stock solution. If the mixture was not dissolved well, DMSO was added. This stock solution was then diluted to the concentrations of 50, 100, 200, 300,400 , and $500 \mathrm{ppm}$. The toxicity test was done in 24 well plates. Each plate at each test concentration contained 20 zebrafish eggs (one embryo per well) and using 4 internal control plates, 1 negative control plate, and 1 solvent (DMSO) control plate. Each control plate contained 24 embryos (1 embryo per well). Plates containing zebrafish embryos were placed at room temperature $\left( \pm 26^{\circ} \mathrm{C}\right)$. The observation was carried out every 24 hrs until 96 hrs (4 days) using inverted microscopes (Olympus) equipped with a computer and camera. The observation was done on living or dead, normal or abnormal, hatched or unhatched (48 hrs only), and teratogenic abnormality. Types of abnormalities were observed include in body axis, head, tail, blood circulation, eyes, heart, pigmentation, somite, and yolk sac. $\mathrm{LC}_{50}$ were determined using a correlational curve between $\log ^{10}$ extract concentration (x-axis) and probit value (y-axis).

\section{RESULTS AND DISCUSSION}

\section{Extract yield}

The concentrated ethanol extract of Javanese ginger was a yellowishbrown paste. The yield of it was $17.77 \%$ on dry matter basis.

\section{Curcuminoid analysis with HPLC}

Curcuminoids are one of the secondary metabolites found in the largest amount in Javanese ginger [6]. Curcuminoids are a group of phenylpropanoid compounds consisting of curcumin, desmethoxycurcumin, and bisdemethoxycurcumin [16]. In this study, the curcuminoid content in ethanol extract of Javanese ginger was determined using HPLC. The standard curcuminoid used consisted of bisdemethoxycurcumin, desmethoxycurcumin, and curcumin. The HPLC chromatogram showed that the peak of standard curcuminoid was obtained at retention time of 7.847 minutes (bisdemethoxycurcumin), 8.463 minutes (desmethoxycurcumin), and 9.110 minutes (curcumin). The peaks in ethanol extract of Javanese ginger were found to be similar to those of the standards (Fig. 1). It was revealed that in ethanol extract of Javanese ginger, curcumin had the highest peak (68.06\%) followed by desmethoxycurcumin $(24.60 \%)$ and bisdemethoxycurcumin $(1.41 \%)$.

These findings suggested that curcumin and desmethoxycurcumin were the dominant curcuminoids. This was in line with the findings of by Mangunwardoyo et al. [17] who reported that curcumin and desmethoxycurcumin were the dominant curcuminoids in Javanese ginger. In this study, the total content of curcuminoids was $10.5 \%$ dry wt.

\section{Shrimp larva and zebrafish embryo toxicity tests}

The BSLT can be used to predict the toxicity level of active components through the $\mathrm{LC}_{50}$ value which is the concentration of a substance needed to kill $50 \%$ of a population. $\mathrm{LC}_{50}$ values at less than $1000 \mathrm{ppm}$ indicate that the tested extract is toxic. Meanwhile, in the ZFET, the extract is considered toxic if growth inhibition or organ abnormalities in zebrafish embryos are observed.

LC values were determined by using a correlational curve between $\log ^{10}$ extract concentration (x-axis) and probit value (y-axis). In this study, the ethanol extract tested on shrimp larvae resulted in an $\mathrm{LC}_{50}$ value of $238.23 \mathrm{ppm}$ (Table 1). This was not too different from the one (210.30 ppm) found by Nurcholis et al. [18].

It is shown in Table 1 that in the ZFET test, $\mathrm{LC}_{50}$ values decreased with increased time. $\mathrm{LC}_{50}$ value at $96 \mathrm{hpf}$ was lower than that at $48 \mathrm{hpf}$ indicating that the material was more toxic as the test animal was exposed for a longer time. This might be caused by the fact that the body immunity of zebrafish decreased with longer exposure, while the extract concentration remained constant.

Overall, $\mathrm{LC}_{50}$ values obtained in the BSLT were higher than those in the ZFET. In the BSLT, the extract was added when the A. salina had already formed larvae while in the ZFET, extract addition was done when zebrafish was in the form of sensitive embryos. In addition, the BSLT was only done over $24 \mathrm{hrs}$, while the observations in the ZFET was done over $96 \mathrm{hrs}$, allowing a longer time for the extract to accumulate in the embryos. The toxicity of curcumin on normal cell was reported

Table 1: $\mathrm{LC}_{50}$ values of ethanol extract tested on shrimp larva (BLST) and ZFET

\begin{tabular}{ll}
\hline Test type & LC $_{\mathbf{5 0}}$ (ppm) \\
\hline BSLT & 238.23 \\
ZFET 48 hpf & 180.52 \\
ZFET 96 hpf & 79.55 \\
\hline
\end{tabular}

hpf: Hours post fertilization, BSLT: Brine shrimp lethality test, ZFET: Zebrafish embryo acute toxicity, $\mathrm{LC}_{50}$ : Lethal concentration $50 \%$ values 
previously using fibroblastic L929 cells showed the percentage viability of cells was $55.52 \%$ in concentration $50 \mu \mathrm{g} / \mathrm{mL}$ (ppm) during $24 \mathrm{hrs}$ exposure time [19]. This report support different cell or stage of development or exposure time of curcumin influenced of toxicity level. The $\mathrm{LC}_{50}$ values obtained in this study were less than $1000 \mathrm{ppm}$, indicating that the extract used in both tests was toxic.

\section{Teratogenic effects of ethanol extract on zebrafish embryos}

Embryos of zebrafish were microscopically assessed for the effects of the extract on the morphology of the embryos. An inhibitory effect resulted from an extract on embryo development causing growth abnormalities is known as a teratogenic effect. The teratogenic effects of ethanol extract on organs and tissues of zebrafish embryos are listed in Table 2. Malformation is considered to be major if it is found in $\geq 50 \%$ of examinations, and minor if $<50 \%$ of examinations.

Results of the observation showed that our ethanol extract gave some teratogenic effects on the development of zebrafish embryos. It is shown in Tabel 1 that a major malformation in embryos treated with ethanol extract was identified for the heart malformation, i.e the pricardial edema.

Table 2: Teratogenic effects of ethanol extract exposure in zebrafish embryos

\begin{tabular}{|c|c|c|}
\hline \multirow[t]{2}{*}{ Body part/organ } & \multicolumn{2}{|c|}{ Abnormality } \\
\hline & $\Sigma^{\mathbf{a}}$ & $(\%)^{b}$ \\
\hline Body axis & 7 & 35 \\
\hline Brain & 0 & 0 \\
\hline Tail & 5 & 25 \\
\hline Blood circulation & 0 & 0 \\
\hline Eyes & 0 & 0 \\
\hline Heart & 10 & $50^{*}$ \\
\hline Jaws & 0 & 0 \\
\hline Otolith & 0 & 0 \\
\hline Pigmentation & 3 & 15 \\
\hline Somite & 9 & 45 \\
\hline Yolk sac & 5 & 25 \\
\hline
\end{tabular}

Minor malformation was identified in body axis, tail, pigmentation, somite, and yolk sac of embryos treated ethanol extract. Embryogenesis in zebrafish is similar to that in higher level vertebrates, including humans, making the zebrafish an ideal model animal for studies in the embryo development process embrio [20,21]. In the negative control, embryo development in eggs was observed in $24 \mathrm{hpf}$ (Fig. 2a). At 48 hpf, embryos developed normally into larvae with perfectly formed organs and a straight body axis (Fig. 2b). Larva of zebrafish is considered normal if it has a straight body axis [22]. At $48 \mathrm{hpf}$, only $50 \%$ embryos treated with $50 \mathrm{ppm}$ concentration hatched. This finding shows that at $50 \mathrm{ppm}$ concentration, our ethanol extract had inhibitory effects on embryo development. The dominant malformation found in $50 \mathrm{ppm}$ treatment was abnormality in the tail (Fig. 2c).

The active compounds of the extract entering pericardial sac could irritate the cells making the heart appear swollen. Exposure with $100 \mathrm{ppm}$ ethanol extract made $70 \%$ of the embryos unhatchable at $48 \mathrm{hpf}$. Compared to those in the control group, larvae in the treatment groups had dominant malformations including a crooked body axis (Fig. 2d, $72 \mathrm{hpf}$ ), pericardial edema (Fig. 2e, $96 \mathrm{hpf}$ ), and yolk sac edema (Fig. 2f, $72 \mathrm{hpf}$ ). The yolk sac functions as a nutrition supply for the embryo. Yolk sac edema is an indication of impaired nutrient adsorption in embryo. This impairment might be caused by malformation in other organs assisting nutrient distribution. This impairment might also lead to the inhibition of nutrient adsorption, undernourished embryos, and the death of embryos. Treatment at a concentration $200 \mathrm{ppm}$ extract (Fig. $2 \mathrm{~g}$ ) made the embryos fail to hatch although some embryo development in the eggs was observed. Embryo failures to develop beyond the chorion could be caused by the failure of the somite to develop. Somite is a tissue which will further differentiate into the backbone and skeletal muscles. Therefore, abnormality in somite development might result in malformation of the body axis and inhibit the hatching process [23]. Treatments at concentrations of 400 and $600 \mathrm{ppm}$ (Fig. $2 \mathrm{~h}$ ) resulted in early death of embryos in the chorion.

Wu et al. [24] reported that the teratogenic effects of curcumin treatment on zebrafish embryos included bent or hook-like tails, spinal column curving, edema in pericardial sac, retarded yolk sac resorption, and shorter body length. The teratogenic effects we found in zebrafish embryos exposed to our ethanol extract were similar. This indicates that

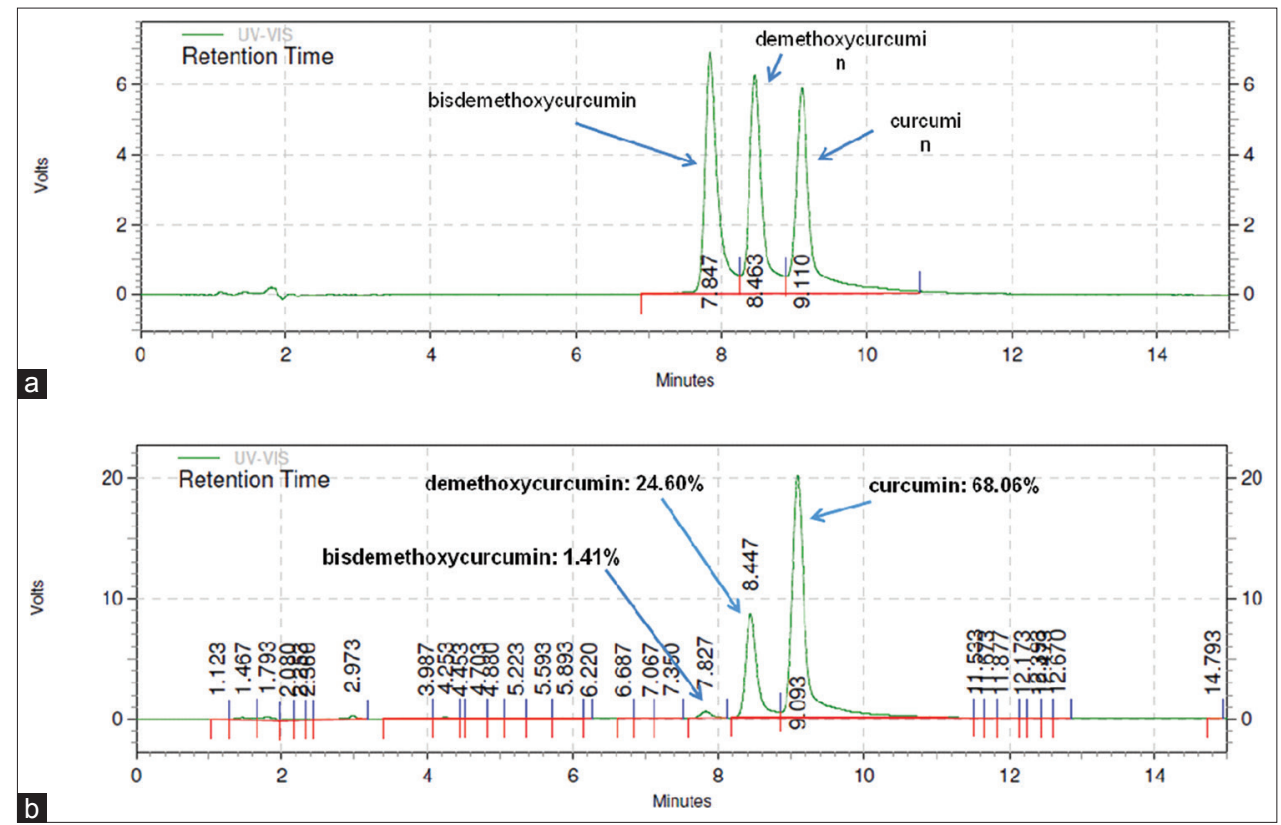

Fig. 1: High-performance liquid chromatography chromatograms of (a) standard curcuminoids and (b) ethanol extract of curcuminoids (Curcuma xanthorrhiza) 

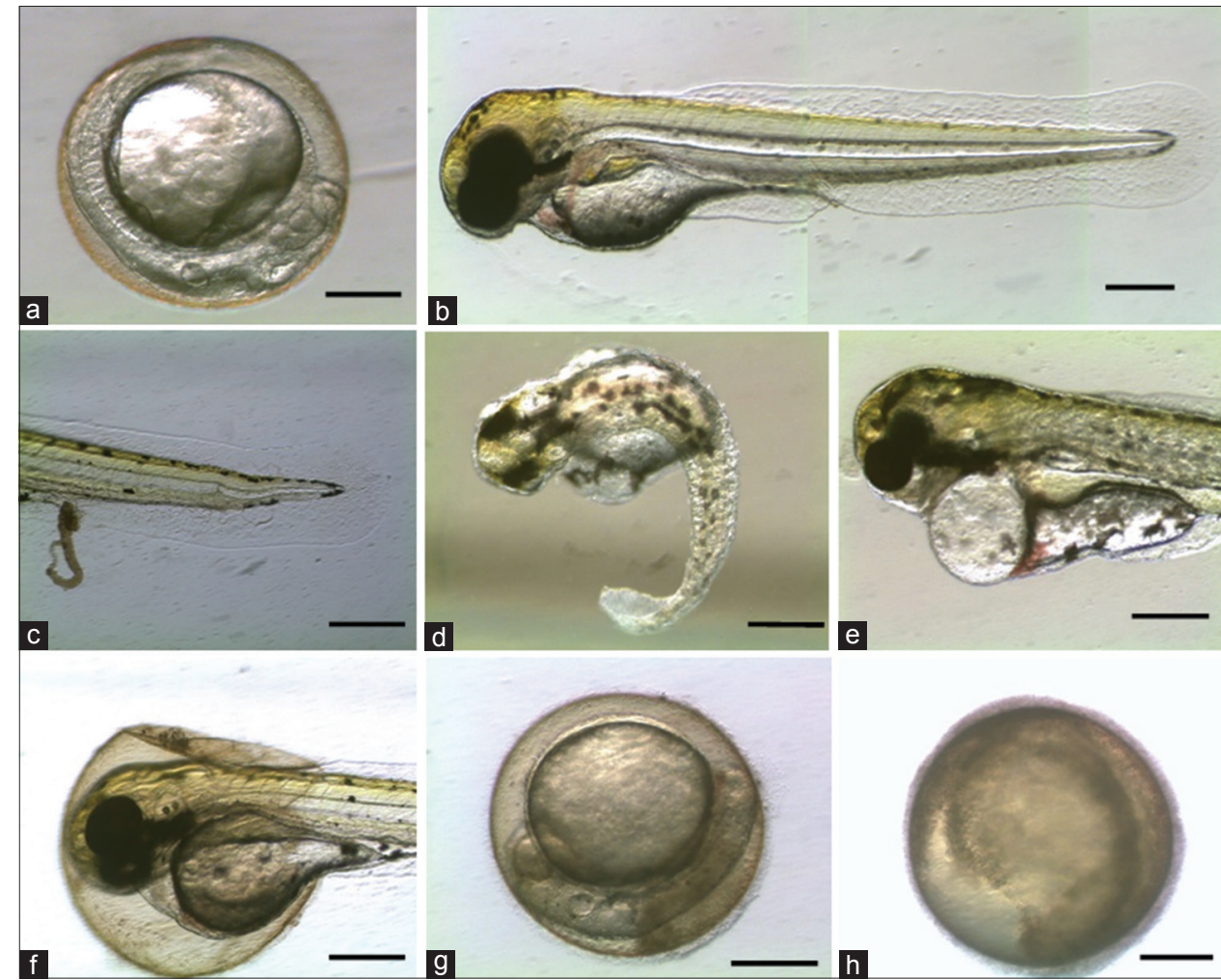

Fig. 2: Morphology of normal zebrafish embryo in control group and some abnormalities in ethanol treatment groups: Normal embryo K-24 hpf (a), K-48 hpf (b), tail malformation (72 hpf, 50 ppm) (c), body axis malformation (72 hpf, 100 ppm) (d), pericardial edema (96 hpf, 100 ppm) (e), yolk sac edema (72 hpf, 100 ppm) (f), 48 hpf, 200 ppm treatment (g), 24 hpf 400 and 600 ppm treatment (h). K: Negative control, hpf: Hour(s) post fertilization (bar $300 \mu \mathrm{m})$

curcumin was the active compound in ethanol extract. This result was in line with the results of HPLC analysis which showed that compared to the other two curcuminoids, cucurmin had the highest content.

\section{CONCLUSION}

Based the results of HPLC, the ethanol extract of $C$. xanthorrhiza from Bogor contained curcuminoids consisting of curcumin at the highest percentage $(68.06 \%)$ followed by desmethoxycurcumin (24.6\%) and bisdemethoxycurcumin (1.41\%). In the BSLT method, the $\mathrm{LC}_{50}$ value of our ethanol extract was $238 \mathrm{ppm}$, whereas for the ZFET method we observed $\mathrm{LC}_{50}$ values of $96 \mathrm{hpf}$ at $80 \mathrm{ppm}$. The ethanol extract of $C$. xanthorrhiza at concentration of $100 \mathrm{ppm}$ caused major malformations of the heart of zebrafish embryos.

\section{REFERENCES}

1. Mary HP, Susheela GK, Jayasree S, Nizzy AM, Rajagopal B, Jeeva S. Phytochemical characterization and antimicrobial activity of Curcuma xanthorrhiza Roxb. Asian Pac J Trop Biomed 2012;2(2):S637-40.

2. Nurcholis W, Ambarsari L, Sari NL, Darusman LK. Curcuminoid contents, antioxidant and anti-inflammatory activities of Curcuma xanthorrhiza Roxb. and Curcuma domestica Val. promising lines from Sukabumi of Indonesia. Di dalam: Prosiding Seminar Nasional Kimia Unesa 2012. 2012a; Febraury, 25. Surabaya. Indonesia.

3. Qader SW, Abdulla MA, Chua LS, Najim N, Zain MM, Hamdan S. Antioxidant, total phenolic content and cytotoxicity evaluation of selected Malaysian plants. Molecules 2011;16(4):3433-43.

4. Devaraj S, Ismail S, Ramanathan S, Yam MF. In vivo toxicological investigation of standardized ethanolic extract of Curcuma xanthorrhiza Roxb. rhizome. J Nat Prod Plant Resour 2010;3(1):67-73.

5. Cheah YH, Nordin FJ, Sarip R, Tee TT, Azimahtol HLP, Sirat HM, et al. Combined xanthorrhizol-curcumin exhibits synergistic growth inhibitory activity via apoptosis induction in human breast cancer cells MDA-MB-231. Cancer Cell Int 2009:9:1-12.

6. Ruslay S, Abas F, Shaari K, Zainal Z, Maulidiani, Sirat H, et al. Characterization of the components present in the active fractions of health gingers (Curcuma xanthorrhiza and Zingiber zerumbet) by HPLC-DAD-ESIMS. Food Chem 2007;104(3):1183-91.

7. Jarikasem S, Thubthimthed S, Chawananoraseth $\mathrm{K}$, Suntorntanasat $\mathrm{T}$. Essential oils from three Curcuma species collected in Thailand. Acta Hortic (ISHS) 2005;3(675):37-40.

8. Itokawa H, Shi Q, Akiyama T, Morris-Natschke SL, Lee KH. Recent advances in the investigation of curcuminoids. Chin Med 2008;3:1-13.

9. Truong L, Harper SL, Tanguay RL. Evaluation of embryotoxicity using the zebrafish model. Methods Mol Biol 2011;691:271-79.

10. Kari G, Rodeck U, Dicker AP. Zebrafish: An emerging model system for human disease and drug discovery. Clin Pharmacol Ther 2007;82(1):70-80

11. Hill AJ, Teraoka H, Heideman W, Peterson RE. Zebrafish as a model vertebrate for investigating chemical toxicity. Toxicol Sci 2005;86:6-19.

12. Srijanto B, Syahbirin G. Optimasi ekstraksi kurkumin dari temu lawak (Curcuma xanthorrhiza Roxb.) secara batch. Di dalam: Prosiding Seminar Nasional Teknik Kimia Universitas Parahyangan 2007; November, 22; Bandung, Indonesia.

13. Jayaprakasha GK, Rao LJ, Sakariah KK. Improved HPLC method for the determination of curcumin, demethoxycurcumin, and bisdemethoxycurcumin. J Agric Food Chem 2002;50(13):3668-72.

14. Meyer BN, Ferrigni NR, Putman JE, Jacobson LB, Nichol DE, McLaughlin JL. Brine shrimps: A convenient general bioassay for active plant constituent. Planta Med 1982;45(5):31-4.

15. The Organization for Economic Co-operation and Development. OECD Guidelines for The Testing of Chemicals No. 236. Fish Embryo Acute Toxicity (FET) Test. Paris, FR: OECD; 2013

16. Panigrahi S, Hirlekar R. A new stability-indicating RP-HPLC method for determination of curcumin: An application to nanoparticulate formulation. Int J Pharm Pharm Sci 2016;8(12):145-55.

17. Mangunwardoyo W, Deasywaty, Usia T. Antimicrobial and identification of active compound Curcuma xanthorrhiza Roxb. IJBAS IJENS 2012;12(1):69-78

18. Nurcholis W, Priosoeryanto BP, Purwakusumah ED, Katayama T, Suzuki T. Antioxidant, cytotoxic activities and total phenolic content of four Indonesian medicinal plants. J Valensi 2012b;2(4):501-10.

19. Athira GK, Jyothi AN. Preparation and characterization of curcumin 
loaded cassava starch nanoparticles with improved cellular absorption. Int J Pharm Pharm Sci 2014;6(10):171-6.

20. Chakraborty C, Hsu CH, Wen ZH, Lin CS, Agoramoorthy G. Zebrafish: A complete animal model for in vivo drug discovery and development. Curr Drug Metab 2009;10(2):116-24.

21. Brannen KC, Panzica-Kelly JM, Danberry TL, Augustine-Rauch KA. Development of a zebrafish embryo teratogenicity assay and quantitative prediction model. Birth Defects Res B Dev Reprod Toxicol 2010;89(1):66-77.
22. Heiden TC, Dengler E, Kao WJ, Heideman W, Peterson RE. Developmental toxicity of low generation PAMAM dendrimers in zebrafish. Toxicol Appl Pharmacol 2007;225(1):70-9.

23. Eeden FJ, Granato M, Schach U, Brand M, Seiki MF, Haffter P, et al. Mutation affecting somite formation and patterning in the zebrafish Danio rerio. Development 1996;123:153-64

24. Wu JY, Lin CY, Lin TW, Ken CF, Wen YD. Curcumin affects development of zebrafish embryo. Biol Pharm Bull 2007;30(7):1336-9. 